\title{
FAUSTO FAWCETT: ENTRE ESSÊNCIA E APARÊNCIA ${ }^{1}$
}

Vítor Castelões Gama (UnB)

Recebido em 23 mai 2018. Vítor Castelões Gama é Doutorando em Literatura e Aprovado em 14 ago 2018. Práticas Sociais pelo Programa de Pós Graduação em Literatura - PósLit - da Universidade de Brasília (UnB), realizando projetos na área de Textualidades: da leitura à escrita. Interessado em pesquisas relativas ao diálogo entre literatura e outras artes, literatura eletrônica, literatura fantástica e ficção científica.

Resumo: O cyberpunk é um dos subgêneros da ficção científica de maior influência no mundo contemporâneo. Mas, assim como o movimento musical que o inspira, as críticas costumam apontar uma superficialidade nas obras. Partindo desta observação, buscamos compreender a dialética entre a essência e aparência nas obras do escritor carioca Fausto Fawcett, a saber: Santa Clara Poltergeist, Básico Instinto, Favelost: (The Book) e Pororoca Rave, com vistas também na visão de mundo romântica, na linha de Michael Löwy e Robert Sayre (2015).

Palavras-chave: Cyberpunk; Fausto Fawcett; Punk; Ficção Científica.

Abstract: Cyberpunk is one of the most influential sub-genres of science fiction in the contemporary world. But, like the musical movement that inspires 
him, criticism usually points to a superficiality in the works. Based on this observation, we sought to understand the dialectic between essence and appearance in the works of the Rio de Janeiro writer Fausto Fawcett, namely: Santa Clara Poltergeist, Basic Instinct, Favelost: (The Book) and Pororoca Rave, also seen in light of the romantic worldview, based on the concepts of Michael Löwy and Robert Sayre (2015).

Keywords: Cyberpunk; Fausto Fawcett; Punk; Science Fiction.

Crime, instinto, é o furor sado-maso, céu sem cor. Meus amigos vão voltar, só que eu já não vou estar lá, obsesso, possuído, na sarjeta esquecido, álcool, sombras, pedras, gritos, qual de nós parou pra pensar (Cólera - Caos Mental Geral)

Mostre-me um país. Limpo sem ditador. Mostreme um povo livre. Sem ódio sem aflição. Não existe mais. Não existe mais. Onde a justiça exista para todos. Pra você, pra mim, pra ele. Sem discriminação. Não existe mais. (Cólera - Não existe mais)

O cyberpunk é um dos subgêneros da ficção científica ${ }^{2}$ mais famosos, segundo o escritor e pesquisador Roberto de Sousa Causo (2013, p. 223), "poucas instâncias dentro da ficção científica tiveram o impacto que o Movimento Cyberpunk teve fora das fronteiras do gênero". Afirmação facilmente comprovada pela atualidade da temática em inúmeros filmes, jogos e no discurso contemporâneo, ao representar um mundo dominado por corporações industriais e marcado pela alta tecnologia que, porém, não é acessível para todos. 
Fausto Fawcett - músico, jornalista e escritor carioca -, é apontado como um dos expoentes deste subgênero no Brasil. Sua primeira obra literária, Santa Clara Poltergeist, é exaltada por outros escritores como Luiz Bras, que a considera "o romance brasileiro mais importante da década de $90^{\prime \prime}{ }^{3}$ Entretanto, esta é uma opinião controversa, uma vez que, "os livros - apesar de, repito, ótimas críticas - jamais abalaram o mercado literário brasileiro. Pouca gente leu; hoje, vinte anos depois, quase ninguém se lembra" (FERNANDES, 2014, p.11-12).

Apesar da originalidade das obras fawcettianas, seu espaço na literatura brasileira não é definido com clareza. O próprio autor não faz questão de conectar-se a outros escritores ou movimentos literários. "No prefácio do Hermano tem uma coisa que eu gosto: quando ele diz que eu flerto com esses elementos de FC sem estar envolvido com eles e muito menos imbuído de alguma ideologia" (FAWCETT, Apud FERNANDES, 2014, p.14-15). Afinal, quais são as suas influências? Para Braulio Tavares (Apud CAUSO, 2013, p.254), a resposta deste questionamento encontra-se no influxo do modernismo, da New Wave da FC e do cyberpunk da década de 90. Já Roberto de Sousa Causo (2013, p.227) aposta no influxo do modernismo e do tropicalismo, enquanto Rodolfo Rorato Londero (2013) acredita no naturalismo e no barroco. É fácil pressupor, então, que não há consenso. Outro exemplo de opinião adversa é a de Cacá Diegues, que rejeita a influência modernista:

O quase centenário modernismo brasileiro sempre se caracterizou por uma espécie de conciliação entre o arcaico e o moderno, dicotomia permanente

3 Disponível em: https:/ficcaocientificabrasileira.wordpress.com/2017/01/31/santaclara-poltergeist/ Acesso em 23.Abr.2018. 
e, às vezes, trágica na sociedade brasileira. Em nome de uma civilização que íamos construir no futuro, destacavam-se os valores do passado que consagrariam sua originalidade utópica. Até mesmo o tropicalismo, último filho temporão do modernismo, tentava disfarçar em caricatura essa indisfarçável nostalgia do futuro [...]. Ali estava um trabalho que não se importava, nem um pouco, com a velha tradição brasileira de alternância entre a busca de uma identidade nacional e a integração no mundo contemporâneo. Em vez disso, um trabalho dedicado a decifrar o sentido do agora, do nosso agora, através da mitologia de um cotidiano virgem de literatura. (2014a, p.7-8)

Na mesma linha de raciocínio encontra-se Hermano Viana, em seu clássico prefácio à primeira edição, no qual ressalta a originalidade do escritor não impingido pela dicotomia passado/ futuro ou pelo afã em buscar as raízes do Brasil e tampouco ligado ao movimento estrangeiro.

Mais importante, a maioria dos escritores cyberpunks (menos, talvez, Rudy Rucker) é constituída, no fundo, por individualistas ingênuos que acreditam na seguinte moral da história: cada pessoa deve ser dona do seu nariz. Fausto, ao contrário, é um escritor que não quer dar nenhuma lição de moral para os seus leitores. As grandes corporações valem a mesma coisa que os grupos da tecnoguerrilha e é tão bom ser dono do seu nariz quanto "dissolver seu ego na matéria em movimento" (VIANA, 2014, p.9)

O mesmo pode ser afirmado em relação a outros escritores brasileiros do subgênero, cuja influência externa parece ser limitada. Haveria então diferenças que justificariam um estudo mais 
detalhado das divergências do movimento no Brasil e no exterior? Neste aspecto, Londero (2013) afirma que o cyberpunk estrangeiro se diferencia do latino-americano por conta de uma visão utópica presente no último, e não no primeiro. Já Roberto de Sousa Causo (2013, p.226) aponta a existência de uma unidade poética no que denominou de "tupinipunk", cujas características principais são a "atitude iconoclasta, a sensualidade, o misticismo, a politização e uma perspectiva de Terceiro Mundo".

Creio que o termo "tupinipunk" seja apropriado porque esta forma de cyberpunk brasileiro é mais relacionado a um dos principais aspectos culturais do Brasil, o sincretismo cultural, do que às características usuais do cyberpunk: a revolução dos computadores, a simbiose homem-máquina, as drogas que expandem a mente, a contracultura de fin de siécle, o comércio de informação e o desejo do Movimento Cyberpunk de inovar sobre tradições mais antigas da FC. (CAUSO, 2013, p.225-226)

As características elencadas pelo pesquisador são extremamente pertinentes e férteis, testemunho da engenhosidade da definição. Entretanto, a influência da visão de mundo romântica, como trabalhada por Michael Löwy e Robert Sayre, também deve ser considerada na conceituação do subgênero. Para estes autores, a cosmovisão romântica é uma forma de expressão cultural derivada das transformações sociais causadas pelo advento do capitalismo e marcado pelo confronto entre a revolta e melancolia (LÖWY; SAYRE, 2015, p.38-39). Como ressalta Marcelo Ridenti,

a crítica baseada em uma visão de mundo romântica incidiria sobre a modernidade como totalidade complexa, que envolveria as relações de produção 
(centradas no valor de troca e no dinheiro, sob o capitalismo), os meios de produção e o estado. Seria uma "autocrítica da modernidade", uma reação formulada de dentro dela própria, e não do exterior, "caracterizada pela convicção dolorosa e melancólica de que o presente carece de certos valores humanos essenciais que foram alienados" no passado, os quais seria preciso recuperar. $(2010$, p.87)

O fato de ser uma crítica interna permite pensar no movimento cyberpunk como tão afetado pela atmosfera liberal e novas tecnologias de comunicação. Nada mais adequado para ponderar sobre os perigos e prazeres da virtualização do que uma obra imersa no ciberespaço. Ademais, como a visão romântica notavelmente realiza um jogo de opostos, é possível explicar melhor as dicotomias presentes nas obras do subgênero: "[A]o mesmo tempo (ou alternadamente) revolucionário e contrarrevolucionário, individualista e comunitário, cosmopolita e nacionalista, realista e fantástico, retrógado e utopista, revoltado e melancólico" (LÖWY; SAYRE, 2015, p.19). Cabe ressaltar que a contraposição do cyberpunk com a estética do romantismo (como gênero e cosmovisão) já havia sido delineada pela pesquisadora Adriana Amaral no livro Visões Perigosas: uma arque-genealogia do cyberpunk:

A herança do romantismo na FC se manifesta principalmente através da ideia de utopia, da nostalgia de se retornar aos valores perdidos; pela estetização do presente; pela rejeição e euforia em relação à modernidade e, principalmente, pela ideia de maquinização do mundo e das relações puramente utilitárias entre os seres humanos. (AMARAL, 2006, p.52) 
Entretanto, para a autora, o romance gótico é o principal, pois seus influxos são essenciais para o desenvolvimento do cyberpunk, seja por meio das técnicas ou tropos literários. Uma perspectiva em consonância com a famosa proposta de Brian Aldiss, para o qual a FC moderna deriva-se de Frankenstein: ou o Prometeu Moderno. Opinião que não é unânime, como ressalta o pesquisador Adam Roberts ao discordar da

[C]rença-manifestada tão amiúde por críticos que quase se aproxima de um dogma-de que (nas palavras de Paul Alkon) "a ficção científica começa com Frankenstein de Mary Shelley". Isso não significa negar que essa novela se provou uma grande influência sobre a subsequente FC. (ROBERTS, 2018, p.191)

Com outro viés, a visão de Michael Löwy e Robert Sayre para a FC é baseada nos trabalhos do escritor e crítico francês Gérard Klein, cujas afinidades vão desde a bagagem teórica até a maneira como a sociedade demonstra-se determinante na definição das formas literárias. Klein (1977, tradução nossa) se indagava do motivo pelo qual a FC americana da década de 60 e 70 se tornou tão diferente das precedentes, «saturada com ruptura, crise, catástrofe iminente, fim do mundo e da humanidade, rejeição dos valores da ciência e até da razão, ceticismo sobre formas e estruturas sociais?"4. A resposta estava presente na angústia e tensão "provocada pela inadaptação desse grupo social à mudança na sociedade mundial, uma mudança que pode implicar na dissolução do grupo social" (KLEIN, 1977, tradução nossa). ${ }^{5}$ Resumidamente:

4 No original: "saturated with rupture, crisis, imminent catastrophe, end of the world and humanity, rejection of the values of science and even of reason, skepticism about social forms and structures?".

5 No original: "provoked by the inadaptation of this social group to change in the world 
Em um primeiro momento-antes da Segunda Guerra Mundial一, a literatura de ficção científica norte-americana é o oposto do romantismo: ela projeta utopias técnico-científicas positivistas para demonstrar que todos os problemas atuais poderiam ter soluções científicas e técnicas. Mas, após a Segunda Guerra Mundial e durante os anos 1950, há dúvida e ceticismo e, a partir dos anos 1960, em um terceiro momento, assiste-se a visões negras de degradação total do mundo, desastre ecológico e até destruição final. (LÖWY; SAYRE, 2015, p.190)

Pelo exposto, a visão de mundo romântica estaria presente nas obras distópicas e não em algumas outras formas da FC, especialmente as que pregam os "valores 'modernos'- o racionalismo utilitário, a eficiência, o progresso científico e tecnológico -, incitando a modernidade a superar-se, a completar a própria evolução, em vez de retornar às origens e mergulhar novamente nos valores perdidos" (LÖWY; SAYRE, 2015, p.51). Tudo leva a conclusão de que a relação da FC com a visão romântica é contenciosa. Mesmo se considerarmos o cyberpunk como um gênero essencialmente distópico, ainda poderíamos cair em uma armadilha. Pois, a advertência dos autores sobre a indústria cultural, na qual "os elementos românticos são neutralizados ou desfigurados pela eliminação de seu vértice crítico, desviados em benefícios de uma cultura essencialmente mercantil" (LÖWY; SAYRE, 2015, p.211), frequentemente também é endereçada às obras do subgênero. Afinal,

[O] romantismo não se reduz a uma lista de temas; trata-se principalmente de uma visão do mundo com estrutura e coerência próprias. Nessa perspectiva, 
apenas um segmento dessa produção merece a designação de "romântico" em sentido pleno: aquele no qual os diferentes temas estão integrados organicamente em um conjunto cujo significado global tende à recusa nostálgica da reificaçãoalienação moderna (LÖWY; SAYRE, 2015, p.212)

Para entender os reflexos da visão romântica nas obras fawcettianas, nos concentraremos em uma parte pouco investigada do subgênero: a relação com o punk (McCAFFERY, 1991). Neste ponto, também chamamos atenção à obra de Adriana Amaral, onde tratou brevemente sobre a influência estilística do gênero musical no literário. Entretanto, há alguns pontos incompatíveis em nossas análises. Enquanto a pesquisadora traça um caminho da visão romântica do romance gótico e do punk para o eletrônico e industrial, nós mantemos o foco nas primeiras formas, pois, nosso escopo não permite a amplitude de uma genealogia, mas, em compensação, é possível delongar-se em alguns tópicos específicos.

Então, como formas tão díspares quanto a visão de mundo romântica, o cyberpunk e o punk se unem? Como veremos mais adiante, o nexo entre as três é a mesma atitude, que junta a cosmovisão com a vontade de atuar nesse horizonte pessimista. Trazer à tona estas relações justifica-se também por ambos os movimentos, musical e literário, serem acusados dos mesmos crimes: superficialidade e falta de crítica. A união entre punk-rock e o romantismo é embasada pelas antologias organizadas por James Rovira, para o qual o rock é essencialmente um fenômeno romântico:

Uma vez que o recebimento do Prêmio Nobel de Literatura em 2016, por Bob Dylan, parece ter tornado inquestionável o potencial literário do rock, 
essa antologia visa não só demonstrar a influência da literatura romântica sobre o rock, que já é objeto de muita atenção, mas argumentar que o próprio rock é uma expressão do final do século $X X$, do romantismo-uma extensão, continuação, parceira ou doppelgänger deste fenômeno dos séculos XVIII e XIX. (ROVIRA, 2018, p.2 - tradução nossa) ${ }^{6}$

Talvez seja igualmente fora de questão o papel social da música, pois é mais do que uma disciplina teórica ou prática artística. "Música é profecia [...] Torna audível o novo mundo que gradualmente se tornará visível, que se imporá e regulará a ordem das coisas; não é apenas a imagem das coisas, mas a transcendência do cotidiano, o arauto do futuro" (ATTALI, 2009, p.11 - tradução nossa). ${ }^{7}$ Com isso em mente analisaremos trechos das obras: Santa Clara Poltergeist, Básico Instinto, Favelost e Pororoca Rave.

Entretanto, nosso objetivo não é buscar uma correlação da literatura com as técnicas musicais em stricto sensu. Apesar das obras fawcettianas permitirem um estudo frutífero nessa linha, enveredar na melopoética exige mais do que o presente artigo pode oferecer. Ademais, a contraposição com as formas musicais já foi estudada detalhadamente por outros pesquisadores. Citamos, por exemplo, a análise do também músico Rogério Skylab, em seu blog Godard City. ${ }^{8}$ Para Skylab, Fawcett pertenceria a uma matriz 6 No original: "Since Bob Dylan's reception of the Nobel Prize in literature in 2016 seems to have placed beyond question rock's literary potential, this anthology seeks not only to demonstrate the influence of Romantic literature on rock, which is already the subject of much attention, but to argue that rock itself is a late-twentieth-century expression of Romanticism-an extension, continuation, partner, or doppelgänger of this eighteenthand nineteenth-century phenomenon."

7 No original: "Music is prophecy [...] It makes audible the new world that will gradually become visible, that will impose itself and regulate the order of things; it is not only the image of things, but the transcending of the everyday, the herald of the future".

8 Disponível em: http://godardcity.blogspot.com/2016/02/a-odisseia-de-faustofawcett.html Acesso em 20.Jul.2018 
poético-lírica da música popular, trabalhando uma tensão entre a linearidade e fragmentação no corpo de suas obras musicais e literárias. Rodolfo Rorato Londero, em sua dissertação de mestrado, trata das relações com o funk.

Fawcett também aproveita estilos musicais-o rap e o funk, por exemplo- em suas obras. [...] Portanto, cyberfunk parece adequado para denominarmos as obras brasileiras, pois, como o punk nos Estados Unidos, o funk também representa, no Brasil, o "sentimento jovem suburbano", ou seja, uma cultura resistente à cultura oficial ou dominante. Porém, a denominação "cyberfunk", por se adequar mais aos romances e contos de Fawcett, exclui as demais obras cyberpunks brasileiras. (LONDERO, 2007, p.104)

O funk e o rap são utilizados nas obras por meio de uma técnica análoga à colagem, o sampling. Ou seja, o uso de outras músicas e batidas para formar uma nova. Mas o que seria o "sentimento jovem suburbano"? Talvez seja o mesmo que está implícito na atitude punk. "O que une todos esses artistas é o que pode ser chamado de uma "atitude" compartilhada - a atitude de desafio às normas culturais e estéticas" (McCAFFERY, 1991, p.287-288 tradução nossa).

E também o punk, para mim, é mais uma coisa cínica. Vamos avacalhar. Vamos pegar o excesso que, para mim, é a coisa mais interessante, a única novidade que existe na vida contemporânea, e vamos mandar uma quinta marcha na banalização, na vulgarização, em qualquer coisa [...] Então eu volto mais punk e mais funk ainda". (FAWCETT, Apud LONDERO, 2010, p.18-19) 
De fato, para Fawcett o punk é representado por esta atitude cínica e contestadora, pois "o punk não se refere somente às "subculturas boêmias", mas também a sujeira urbana. A junção entre alta tecnologia e sujeira das ruas realiza-se plenamente ao romance de Fawcett" (LONDERO, 2007, p.150). O que é esse conceito críptico chamado atitude punk? Parafraseando Santo Agostinho: se ninguém me pergunta o que é, eu sei, mas, se quero explicar a quem me pergunta, não o sei. Arriscamos: é uma reação ao tédio e indiferença por meio do DIY (do it yourself), ou, "faça você mesmo". ${ }^{9}$ Esteticamente é representando pela repetição, simplicidade, ressignificação e velocidade. Há também uma rejeição explícita do passado, do presente ou do futuro. Clama-se pela destruição de tudo, inclusive você mesmo. Contraditoriamente, a atitude punk também é marcada pelo otimismo. Para o jornalista Lester Bangs (2003, p.258), o movimento representa "um sonho utópico fundamental e milenar: se você der licença às pessoas para serem tão ultrajantes quanto quiserem de qualquer forma que elas possam sonhar, elas serão criativas e farão algo de bom". ${ }^{10}$

Aquele Estilo encurvado, o couro como armadura, um cabelo zoado, o sentimento de não ser parte da nada, de não se encaixar, de estar muito à frente ou muito atrás, de não aceitar abrir mão do seu jeito, de não se conformar com as regras impostas, com os velhos manuais, mas também sem ter o que propor, já que a vida não fazia sentido e o futuro não existia. (PAIVA; NASCIMENTO, 2016, p.29)

9 O DIY é uma perspectiva ética que prega a autossuficiência, crie as suas próprias alternativas, seus produtos. O conceito não é uma novidade trazida pelo punk, porém, muito de sua popularização deve-se ao movimento.

10 No original: "a fundamental and age-old Utopian dream: that if you give people the license to be as outrageous as they want in absolutely any fashion they can dream up, they'll be creative about it, and do something good besides." 
Afinal, em um mundo estranhado, em constante movimento, é possível se afirmar como sujeito ou mudar o mundo? Nesta época "não apenas a revolução não é mais o veículo da utopia, não apenas se torna o inimigo, mas o próprio ideal utópico é, dali em diante, para esse jovem desencantado, um objetivo indesejável e impossível" (LÖWY; SAYRE, 2015, p.156).

Nos cansamos de ouvir sobre uma suposta geração alienada manobrada pelo poder, a Geração Ai-5, a Geração Coca-Cola, que não teria nascido em tempo de fazer a revolução nas estepes russas, nas fábricas, no campo, não teria marchado com Mao, nem com Che pelas selvas de Sierra Madre e da Bolívia. Aqueles, sim, seriam tempos de revolução. Os ideais da esquerda revolucionária se isolaram e não empolgavam as massas. [...] Por mais justa que fosse a causa, o método era questionado. Há possibilidade de se fazer revolução sem dor, morte, sangue? A arte tem esse poder? A música mobiliza? O Rock muda o mundo? E o Punk? (PAIVA; NASCIMENTO, 2016, p.66)

O punk está imbuído da nostalgia de um passado de revolução, mas, no qual as utopias foram deslocadas no tempo. Como produto de seus atos restava um desejo "que não parece apostar num futuro ('horizonte negro'), sem planos, sem finalismos [...] Agora, antes que acabe o mundo" (CAIAFA, 1985, p.63). O objetivo é contextualizar, fazer-se presente no mundo. Estou vivo ou apenas tenho as memórias dos tempos em que eu era alguém. De que fazia algo e tudo parecia simples. Nesse instante parecido como "Véu de Maya" da "Matrix", o cyber/punk expõe sua vontade de acabar com as pretensões e passar da aparência à essência. Porém, seria inocente crer no transcendentalismo vindo da sarjeta? 
Antes de entendermos a dicotomia entre essência e aparência é necessário voltar à questão estética. Separar etimologicamente o cyberpunk permite contrapor os mecanismos que lhe dão forma narrativa. Assim, de pronto, percebe-se a contradição inscrita no nome, no qual cyber, derivado do grego kybernetes (piloto, ou governador), é quase que oposto à anarquia do punk.

A cibernética representa 0 endurecimento e a exteriorização de certas formas vitais de conhecimento, a cristalização do espírito cartesiano em objetos materiais e mercadorias. [...] Assim como o punk, mas ao contrário. Uma recusa auto-entorpecedora e auto-mutilante de dignificar ou confiar em qualquer coisa que trazida do mundo atual, até mesmo o corpo humano, tudo pela promessa de autenticidade tão indefinível que jamais poderá ser conhecida, e muito menos cooptada. (CSICSERY-RONAY, 1991, p.185 tradução nossa $)^{11}$

O cyberpunk atua na fronteira do controle e sua ausência. Como o movimento que o inspirou, "significa o caos em todos os níveis, mas isso só é possível porque o estilo em si é tão bem ordenado. $\mathrm{O}$ caos se consolida em um todo significativo" (HEBDIGE, 2008, p.113 tradução nossa). ${ }^{12}$ Uma contradição flagrante ao observar o quanto uma "roda punk" respeita suas fronteiras ou quão fluídas e livres são as comunicações de cenas em outros países. Nas obras literárias, esse caos é consolidado por meio de um substrato negativo, como

11 No original: "Cybernetics represents the hardening and exteriorization of certain vital forms of knowledge, the crystallization of the Cartesian spirit into material objects and commodities. [...] So is punk, but in reverse. A self-stupefying and self-mutilating refusal to dignify or trust anything that has brought about the present world, even the human body, all for the promise of authenticity so undefinable it can't ever be know, let alone co-opted." 12 No original: "signified chaos at every level, but this was only possible because the style itself was so thoroughly ordered. The chaos cohered as a meaningful whole." 
se fosse um método apofático. Por exemplo, na imagem de uma metrópole suja, apinhada de letreiros e das diversas luzes que não iluminam, jaz uma impressão negativa do que é faltante. Isto é, uma cidade limpa, justa e talvez utópica. De um andróide fica a alusão a um corpo humano que não pôde ser aceito, de uma identidade que foi negada.

O que é banido, excluído e separado pode resultar em um "aparecimento súbito e maciço de estranheza", que, segundo Kristeva, é sentido como se fosse um membro amputado que-"agora me atormenta como radicalmente faltante". Mas apenas como resultado de evocar sua presença, que se pode aniquilá-lo. Se não for reconhecido, "à beira da inexistência e da alucinação", o abjeto se torna a "matéria-prima" da cultura. (SCANLAN, 2005, p.165, tradução nossa) ${ }^{13}$

Para evocar esta presença, "comunicar desordem, a linguagem apropriada deve primeiro ser selecionada, mesmo que seja para ser subvertida" (HEBDIGE, 2008, p.88 - tradução nossa). ${ }^{14}$ Isto é, a linguagem do cyber/punk funciona como um mascaramento, transformando o conhecido em desconhecido. Pensemos nas histórias de andróides indistiguíveis dos seres humanos, a forma humana não é uma das imagens mais reconhecíveis de todas? Porém, sua destruição é muito frutífera filosoficamente e socialmente. O que demonstra como nossa compreensão do mundo é parcial e pode ser expandida. Isto é 13 No original: "What is banished, excluded and made separate may result in a 'massive and sudden emergence of uncanniness', which, according to Kristeva, one encounters as if it were a detached limb - it 'now harries me as radically separate'. But only as a result of its bringing to presence can it annihilate. If left unacknowledged 'on the edge of nonexistence and hallucination' the abject becomer the 'primer' of culture".

14 No original: "to communicate disorder, the appropriate language must first be selected, even if it is to be subverted." 
por que ultrapassando a aparência do cyberpunk, o "fantasma na máquina" transforma-se em um referencial para novas formas de enxergar a realidade.

Entretanto, a crítica em geral fica divida pela opinião de que tais movimentos não passam de fachada: choque, agressão ou a sublimação de impulsos sexuais, sem efetivamente propor alternativas à sociedade que criticam. Em outras palavras, que quebrar as vidraças de uma igreja não desfaz os anos de inquisição, que confrontar a polícia apenas justifica os financiamentos mais pesados por parte do Estado. Ou, como diz Darko Suvin (1991, p.357), responder ao chamado para destruir as bases, enquanto as estruturas mantêm-se intactas. "Dizendo de forma branda, é difícil de vislumbrar os motivos político-estéticos 'integrados', das subculturas alienadas que adotam as ferramentas de alta-tecnologia do establishment do qual são supostamente alienadas" (CSICSERYRONAY, 1991, p.183, tradução nossa). ${ }^{15}$

Porém, o estilo, mesmo que subversivo, nem sempre é visto como mensagem. É mais provável que seja visto como ruído. Como interpretar jovens andróginos, vestidos com roupas sadomasoquistas? “Mas o punk não é só visual, só música crassa. É também uma crítica e um ataque frontal a uma sociedade exploradora, estagnada e estagnante nos seus próprios vícios. Os punks não querem mais esperar o tão prometido fim do mundo" (BIVAR, 1983, p.49). Similarmente, como interpretar uma forma literária que se utiliza de todos os "gadgets" contemporâneos? O diálogo cinematográfico seria um indicativo da falta de 15 No original: To put it mildly, it's hard to see the "integrated" political-aesthetic motives of alienated subcultures that adopt the high-tech tools of the establishment they are supposedly alienated from. 
crítica justamente por ter seu discurso cooptado pelo capital hollywoodiano: as obras de David Cronenberg criticam algo?

Tomado pelo que mostra, o cyber/punk é caracterizado como um mundo de simulacro, onde a aparência é tudo e nada ao mesmo tempo. Bivar (1983, p.103-104) comenta em uma entrevista sobre o visual agressivo do punk rock que demonstra este ponto. "Tikinho, guitarrista da Lixomania, responde: 'É a única maneira de chamarmos a atenção para o caos em que vivemos. Se eu fosse mais um office-boy da rua 7 de Abril, você não estaria me entrevistando" Portanto, essência e aparência não são simples de se identificar e o estilo pode ser utilizado como forma de comunicação e resistência.

[O] desafio à hegemonia que as subculturas representam não é emitido diretamente por elas. Pelo contrário, é expresso obliquamente, pelo estilo. As objeções são apresentadas, as contradições exibidas (e, como veremos, "resolvidas magicamente") no nível profundamente superficial das aparências: isto é, no nível dos signos. (HEBDIGE, 2008, p.17 - tradução nossa) ${ }^{16}$

A luta pelo controle e subversão dos significados é instável. Os punks lidam com estes limites, "seu exercício é essa relação beligerante de fronteira com o que os envolve e entre si. As investidas da moda existem como um móvel que eles constantemente deslocam e que assim utilizam como propulsão" (CAIAFA, 1985, p.120). As palavras, os ícones são ressignificados, fonte da força criativa do movimento. O cyber, antes "controlado", passou a ser visto como simples sinônimo para o digital. O ciberespaço de 16 No original: "the challenge to hegemony which subcultures represent is not issued directly by them. Rather it is expressed obliquely, in style. The objections are lodged, the contradictions displayed (and, as we shall see, 'magically resolved') at the profoundly superficial level of appearences: that is, at the level of signs." 
Gibson virou um lugar de extrema liberdade, liberdade do corpo, das potencialidades, dos contatos. Utilizando o mínimo espaço possível e com os instrumentos que lhe são dados (frequentemente antiquados ou mudos), o cyber/punk realiza um trabalho de alquimista. Cria-se o ouro a partir do chumbo (das balas).

Os punks apostam em que os efeitos produzidos por tal e tal coisas podem ser produzidos por outros meios. Nunca é o meio que se poderia esperar, mas sempre um outro que se cria, se artificia para essa produção. O punk tem então uma tarefa, ele trabalha os recursos e os transforma. E essa transformação é sempre do mínimo em direção ao máximo. (CAIAFA, 1985, p.133)

Ou seja, partindo dos mais variados significantes, da aparência, o resultado da transmutação literária é uma essência. Neste sentido, o papel da crítica é entender como o escritor ou o músico obtém uma síntese poética da realidade, caso a obtenha.

[A] verdadeira arte, aprofunda-se sempre na busca daqueles momentos mais essenciais que se acham ocultos sob a capa dos fenômenos; mas não representa esses momentos essenciais de maneira abstrata, fazendo abstração dos fenômenos e contrapondo-se a àqueles, e sim apreende exatamente aquele processo dialético vital pelo qual a essência se transforma em fenômeno, se revela no fenômeno, fixando, também, aquele aspecto do mesmo processo segundo o qual o fenômeno manifesta, na sua mobilidade, a sua própria essência. (LUKÁCS, 1965, p.29)

Pode até parecer que é fácil levantar a capa e expor o interior. Mas, na verdade, definir o que é essência é tão complexo quanto sair da superficialidade. Na questão da aparência, o processo criativo 
de Fausto Fawcett se mostra inundado pelas diversas mídias: televisão, música, cinema. O próprio nome artístico do autor é uma referência e homenagem à atriz Farrah Fawcett. Um exemplo claro são os personagens principais de Pororoca Rave: uma dupla de DJs conhecida por "Duo Coletivo Fugitivo Sound".

Como outras turmas de DJs que se misturam com músicos, que se misturam com artistas plásticos, que se misturam, se juntam às rapaziadas criativas na manipulação das parafernálias computacionais, dos instrumentos de tecladaria digital. Misturamse com redatores de programas televisivos e roteiristas cinematográficos, assim como poetas de falação repentista ou teatral de eloquência alucinada, verve inusitada. (FAWCETT, 2015, p.10)

Uma leitura mais detalhada do primeiro romance, Santa Clara Poltergeist, corrobora a impressão de heterogeneidade avassaladora da obra, marcada por uma repetição desconfortante. "Rasteiros cumulus nimbus nublam crateras abertas por motoniveladoras a serviço de um pool de construtoras de edifícios inteligentes. Vigas de chips serão enterradas junto com labirintos de fibras óticas e estratégicos focos de cerâmica supercondutora" (FAWCETT, 2014, p.18). Mesmo com a repetição nas linhas seguintes de várias palavras (as nuvens, neblina olho, ótica, nitrato) não há uma desaceleração. Ao contrário, as palavras entram em confronto com as imagens, pois na leitura não é possível imaginar a representação de uma nuvem cobrindo vagarosamente os buracos na estrada. Embate que se repetirá na maior parte do romance. Enfim, a narrativa é de extrema visualidade e ritmo incessante.

Em Santa Clara, a constante presença de fotos pornográficas digitais granuladas e imagens de 
placas de circuitos de computador impressas nas margens ou em alternância com as páginas de texto reforçam os temas de sexo e tecnologia do romance, criando uma montagem visual. A chave dessa narrativa é que todas as metáforas são sexuais, combinando conceitos como o "Big Bang" da astrofísica, com a sexualidade tântrica hindu e a energia prana. (GINWAY, 2005, p.168)

As metáforas sexuais servem para aumentar o caos e contradição. A começar pelo oxímoro da personagem Santa Clara Poltergeist, sacerdotisa da desmaterialização por meio da matéria: ressuscita os outros pela petit mort do orgasmo. Ao nível semântico fomenta a ambiguidade, o big bang pode se referir à origem do universo, a uma grande orgia, uma explosão, um tiro. E todos os sentidos estariam corretos em algum momento da narrativa, muitas vezes concomitantemente. Processo levado adiante em Favelost por meio da subversão criativa do punk, no lema "nada se perde, nada se cria, tudo se transforma". Do mínimo ao máximo em 1 segundo.

[E]nfim, do nada pode surgir um outro tipo de utilização pra qualquer tradição graças à digitalização mundial, graças à dnalização mundial. Promiscuidade destrutiva criando. Migração de técnicas mitologias. Muito além de qualquer antropofagia. O que tem de cultura polonesa na comida do Chile, o que tem de detalhe romeno numa nova concepção de rituais espíritas em Brasília, o que tem de xamã indígena servindo de assistente de laboratório farmacêutico ou biológico. (FAWCETT, 2012, p.22)

Não é isso a proposta das inversões? Por exemplo, quando afirma que as "Igualdades, Fraternidades, Liberdades estão perturbadas pelos novos mandamentos do Humanismo 
Encurralado: a Velocidade, a Instabilidade e a Precariedade, fora a brutalidade dos fatos e existências" (FAWCETT, 2012, p.25). Mas, ao mesmo tempo, que é criativo, é precário e brutal. Em contraposição, a destruição criativa da globalização é denunciada em seus abusos e falências da globalização, por exemplo, no conto "Vanuza e Rachid", em Básico Instinto, no qual a Amazônia é constantemente devassada por forças externas e internas.

[E]steve numa tribo de índios que ficara em consignação numa universidade americana vendo televisão e vivendo em paisagens artificiais $\mathrm{e}$ comendo papinhas experimentais da indústria alimentícia astronáutica. Recolocados na selva sem nada daquilo enlouqueceram. Passaram a sentir cold turkeys de aculturação e invadiram povoados e cidadezinhas à procura de eletrodomésticos, TVs, geringonças, crimes, iogurtes, papel de parede com paisagem a fim de sentirem algum alívio ambiental. (FAWCETT, 2014a, p.107)

Afinal, é possível afirmar que tais obras dão combustível para apontar a superficialidade do cyberpunk, uma vez que expõe um livre escoar das imagens, uma sexualidade desenfreada, sem um julgamento moral óbvio. Entretanto, há a busca concomitante de uma essência.

O que há por trás de cada pensamento ou sentimento ou vontade ou trecho de matéria ou obscenidade ou manifestações de matéria? 0 invisível em Copa é muito vulgar, o transcendental é totalmente banal e o misticismo erotizou-se de vez. Natureza humana escancarada, provocada por todos os lados no bairro. Ser e não ser juntos novamente. (FAWCETT, 2014, p.88) 
No conto que nomeia a coletânea de histórias Básico Instinto, esboça-se a busca da essência. Inicialmente, essa essência é exaltada por ser algo que não está disponível, ou à venda no mundo contemporâneo.

Reza a lenda filosófica que existem forças caóticas inauguradoras do universo, da vida, da morte, da natureza, consignadas dentro de nós mandando continuamente sinais avisando-nos da nossa insignificância, da nossa obsolescência, da nossa frágil arrogância civilizatórias. [...] Sinais que são tentações de decadência e transcendência voraz acionando a nossa nostalgia de quando ainda não éramos humanos, apenas fluxo de mutações inorgânicas ou primitivas mutações orgânicas. (FAWCETT, 2014a, p.112)

Para Michael Löwy e Robert Sayre (2015, p.47), o "repúdio à realidade social atual, experiência de perda, nostalgia melancólica e a procura do que foi perdido", seriam os principais componentes da visão romântica. A realidade vista não poderia ser mais desencorajadora.

Visão obscena da raça humana. Excessos de megacidades, principalmente as do terceiro mundo. Megacidades situadas em países onde o verniz da civilização é bem ralo. [...] Povos colocados em estado de semi barbárie adrenalizada e criminosaapática à espera de salvações ou multirões desconcertantes e maníacos. Sem acesso às benesses tecnológicas. Com acesso clandestino e perigoso a todas as benesses e sucatas tecnológicas. (FAWCETT, 2014a, p.113-114)

Frente a este contexto, a reação normal do cidadão comum é buscar algo além deste mundo. 
Todos sonham com céus e mundos melhores, todos sonham e trabalham rumo a modelos de excelência visando o escape da selvageria, da pobreza, da mediocridade, da ignorância. $E$ a veia platônica pulsa desesperada enquanto as forças caóticas da violência primordial são cutucadas com vara curta pelo excesso de poluição humana das megacidades mundiais que conferem um clima de instabilidade purgatória ao mundo dito contemporâneo, poluído de heranças, estirpes, tradições, mutações, espécies culturais e biológicas. (FAWCETT, 2014a, p.113)

A resposta cyber/punk encontra fulcro na utopia/distopia e na nostalgia. As opções para o indivíduo ou personagem são poucas: revoltar-se contra a sociedade, reformar o mundo ou acomodar-se na crença de que haverá um futuro melhor. Crer que há por detrás de qualquer verborragia ou elucubração tecno-anárquica, algo que o racionalismo não poderia apagar. Uma posição que Fawcett parece relutantemente endossar.

Apesar de todas as conquistas da modernidade humanista, o buraco da transcendência não foi tapado. Sonhos de eternidades e palácios de sobrevivência além, num tempo além de primórdios luminosos e inauguradores de tudo que existe, bem, esses sonhos ainda rolam firmes nos corações e mentes [...] Todos acreditam que existem dentro de si um elemento espiritual oculto que precisa ser materializado. (FAWCETT, 2014a, p.116)

O caminho para a "salvação" é por meio das "artes plásticas, literatura, música, cinema, que, junto às folclóricas manifestações, têm que enfrentar, adaptar-se, conviver com a selvageria suculenta que há cem anos, pelo menos, toma conta de tudo através das massificações 
audiovisuais" (FAWCETT, 2012, p.26). Indo mais a fundo, as obras aproximam-se de uma perspectiva de desconstrução derridiana onde a memória humana é um grande processador, operando as "sensações do Verbo, quero dizer, da linguagem que faz do mundo a sua semelhança, e faz dele refém das associações, evocações, arbitrariedades simbólicas. Verbo é o Virtual Absoluto" (FAWCETT, 2014, p.107). A linguagem é o veículo para os outros mundos.

A física já entregou já muito os pontos do positivismo e admite o encontro da sua linguagem (cujo simbolismo é mais contundente, pois cria universos verbais que atiçam a curiosidade e nos conduzem a intrincadas aventuras de raciocínios dignas das intrincadas aventuras da matéria à qual estão relacionados) com o simbolismo das cosmogonias religiosas. (FAWCETT, 2014, p.52)

Agora a essência do mundo e da vivência humana é parte da física quântica e não mais do discurso religioso. "A espiritualidade humanizada, humanista, e a espiritualidade sagrada de igrejas e religiosos de todos os tempos estão empatadas" (FAWCETT, 2012, p.161). Em Santa Clara, os novos templos que buscam o "sagrado" são os supercolisores.

Com esses gigantescos colisores, os pesquisadores vão chegar mais rapidamente ao detalhe que falta para se detectar e corroborar a existência do indivisível em se tratando de matéria. O ponto final. O último dos quarks (os construtores dos prótons e nêutrons que constituem o núcleo dos átomos). 0 que os físicos chamam TOP. (FAWCETT, 2014, p.53)

De fato, o quark TOP foi descoberto seis anos depois da primeira publicação da obra. Mas isso não trouxe nenhum "progresso" 
para a vida social periférica. Não houve um súbito momento de iluminação no qual tomaríamos consciência de nossa condição humana e coletiva. Uma partícula elementar não foi suficiente, pois para entender o que ela significa é necessário compreender - linguajar científico. A música é outro caminho para perceber o mundo, pois "hoje, nenhuma teorização realizada através da linguagem ou da matemática pode ser suficiente por mais tempo; é incapaz de explicar o que é essencial no tempo - o qualitativo e o fluido, ameaças e violência" (ATTALI, 2009, p.4). ${ }^{17}$ Por esse motivo, em Pororoca Rave foi necessário modificar o fundamento científico que servia de base.

Nós, pesquisadores de sonoridades, sempre sentimos certa inveja do pessoal que lida com luminosidades e fótons e ondas de luz e gostaríamos também de perscrutar o universo atrás de uma sonoridade primordial, o OM tão alardeado por místicos. Só que, como você sabe, o som não se propaga no espaço, daí que ficamos até pouco tempo atrás nos sentindo inferiores a astrônomos e astrofísicos que tinham um eco luminoso dos primórdios guiando suas pesquisas. Só que recentemente descobriram que num átimo da explosão inicial havia uma vibração. E se tem vibração, tem som. Voilá. Radiação de fundo sonoro do Big Bang. (FAWCETT, 2015, p.10)

Descobrir o "som puro" é um desejo clássico da música eletrônica. A banda Kraftwerk comenta em uma entrevista com Lester Bangs (2003, p.158): "Estamos muito interessados na origem da música, a fonte da música. O som puro é algo que

17 No original: "today, no theorizing accomplished through language or mathematics can suffice any longer; it is incapable of accounting for what is essential in time-the qualitative and the fluid, threats and violence." 
gostaríamos muito de alcançar." ${ }^{18}$ Os DJs de Pororoca Rave não pensam diferente.

Porque o mote do trabalho desses garotos é descobrir a radiação de fundo do Big Bang contido nas superfícies, nos organismos, nos corpos e principalmente no espectro eletromagnético cheio de sons e sinais a postos para se transformarem em música estranha e sedutora. Vasculhar pulsares, auroras boreais, supernovas, quasares, buracos negros, movimentações banais dos corpos por aí. Qual o som, qual o som dos primórdios, qual o som do átomo, qual o som do quark, qual o som do fóton, qual o som, qual o som do elétron, do nêutron, qual o som oculto nas paragens cósmicas? (FAWCETT, 2015, p.12)

Para este tipo de pesquisa não é mais necessário os supercolisores, substituídos pelo Observatório de Ondas Gravitacionais por Interferometria a Laser (LIGO). Intrigantemente, a estrutura narrativa de Pororoca Rave assemelha-se à história dos pesquisadores envolvidos com o LIGO, que "ao longo do tempo de vida dos observatórios, cientistas vão reconstruir uma ressoante e dissonante trilha sonora para acompanhar o filme mudo da história do universo que a humanidade compilou" (LEVIN, 2016, p.13).

Ondas gravitacionais não são ondas sonoras, mas podem ser convertidas em som por pura tecnologia analógica, muito semelhante a como uma onda na corda de uma guitarra pode ser convertida em som mediante um amplificador convencional. (LEVIN, 2016, p.21)

Estas ondas ocorrem quando objetos maciços se fundem, criando uma curvatura no tempo-espaço que envia ondulações 18 No original: "We are very much interested in origin of music, the source of music. The pure sound is something we would very much like to achieve." 
pelo universo. O big bang foi um desses eventos que por meio dessa onda causou e causa até hoje uma espécie de ruído inaudível. O objetivo do observatório é detectar este som.

O arquétipo do personagem romântico na música eletrônica encontra-se no DJ solitário e suas máquinas, flâneur contemporâneo. Logo, é incomum haver uma dupla de DJs, porém, a quantidade faz sentido quando se percebe que os observatórios também devem ser erguidos aos pares.

Construa outro, porque precisa de dois. Pelo menos dois. Situe o segundo longe do primeiro. Ele serve não só para confirmar uma detecção como real e não um falso alarme, mas também para certificar a localização do som. Ter dois detectores na Terra é tão útil como ter duas orelhas na cabeça. (LEVIN, 2016, p.89)

No final de 2015 fora gravado um sinal consistente com a fusão de dois buracos negros, provando a existência das ondas gravitacionais. Novamente, pouco depois da publicação da obra de Fawcett. Enfim há um som primordial presente em todos os cantos do universo, pois a linguagem da música é universal. Mas, voltamos ao dilema dos quarks em Santa Clara Poltergeist, isso é uma essência ou apenas uma abstração? Saber que temos um denominador em comum não mudou muita coisa porque criamos as nossas diferenças. De que adiantou saber que somos poeira de estrelas, que vibramos ao mesmo som?

Questões que gostaria que tivéssemos a resposta, mas não temos. As obras de Fawcett não confortam esse anseio. Em uma mistura de balela e pensamentos densos, encontram-se algumas passagens cruelmente autorreflexivas. 
Esse blá-blá-blá contracultural clonado de niilismos, dadaísmos, anarquismos do começo do século XX e massificado (aí, sim, a novidade) pela mídia televisiva cobrindo tudo, repercutindo tudo, esse papo reviveu de forma fanfarrônica o misticismo e o romantismo que envolviam a transcendência, só que em função do segmento de exploração comercial chamado juventude que, além de já ter como conceito de venda completado cinquenta anos de vida comercial e motivação mental, já está devidamente amainado e sem poder de fogo. (FAWCETT, 2012, p.160)

Como um “bom” punk, Fawcett puxa o próprio tapete. A atitude foi divertida enquanto durou, antes de ser massificada e explorada. Mas, realmente acabou? A arte não tem mais lugar no mundo? 0 que o autor faz e diz são diferentes, porque continuar escrevendo? Para cada "midianfíbios", sociedade podre e saturada, há um personagem praticando a própria arte. Soterrado pela violência, anarquia e verborragia desvairada, esconde-se uma nostalgia da cultura humanista. Uma opinião que Fawcett tenta repudiar veementemente, mas que continua representando nos romances e contos. Aqui está a verdadeira essência das obras, a evidência do ser humano por detrás da escrita e da leitura. Falhar na busca da essência e continua procurando, sem perceber que o essencial é viver o percurso. A essência é falhar.

Não perceber todo o mascaramento na saturação das imagens, e, por conta disso, criticar o cyber/punk pela superficialidade da aparência é uma interpretação injusta. Similarmente, Lester Bangs comenta sobre as pessoas que falavam que o punk não passa de uma moda juvenil, que não há coerência, ou que vestir uma camisa 
de banda não é um ato de revolução. O que é uma verdade parcial, vestir apenas uma camisa não é suficiente, mas, eles estão errados, "porque no mínimo tudo isso equivale a um gesto de fé nas possibilidades individuais e de massa não realizadas, o que conta muito em uma época em que há muitas vozes que lhe diriam que todo comportamento humano pode ser reduzido a uma fórmula" (BANGS, 2003, p.258 - tradução nossa). ${ }^{19}$ Acreditar no cyber/punk é também acreditar na própria potência e com isto trazer uma forma de resistência às próprias contradições românticas que o marcam.

\section{REFERÊNCIAS}

AMARAL, Adriana (2006). Visões Perigosas: uma arque-genealogia do cyberpunk. Porto Alegre: Sulina.

ATTALI, Jacques (2009). Noise: the political economy of music. 10a Impressão. Minneapolis: University of Minnesota Press,.

BANGS, Lester (2003). Psychotic reaction and carburetor dung. New York: Random House.

BIVAR, Antonio (1983). O que é punk. 2.ed. São Paulo: Editora Brasiliense.

CAIAFA, Janice (1985). Movimento Punk na Cidade: A invasão dos bandos sub. Rio de Janeiro: Jorge Zahar Editor.

CAUSO, Roberto de Sousa (2013). Ondas nas praias de um mundo sombrio: New Wave e Cyberpunk no Brasil. (Tese de Doutorado em Estudos Linguísticos em Inglês) 315f. Universidade de São Paulo, São Paulo.

CSICSERY-RONAY, Istvan (1991). "Cyberpunk and Neuromanticism". In: McCAFFERY, Larry (Org). Storming the reality studio: A casebook of cyberpunk and postmodern science fiction. London: Duke University Press. p.182-193.

DIEGUES, Cacá (2014a). "Apresentação". In: FAWCETT, Fausto. Básico Instinto. Curitiba: Encrenca. p.7-11.

19 No original: "Because at the very least all of this amount to a gesture of faith in mass and individual unrealized possibilities, which counts for a lot in an era when there are plenty of voices who would tell you that all human behavior can be reduced to a formula." 
FAWCETT, Fausto (2012). Favelost (the Book). São Paulo: Martins Fontes. (2014). Santa Clara Poltergeist. Curitiba: Encrenca. (2014a). Básico Instinto. Curitiba: Encrenca. (2015). Pororoca Rave. Rio de Janeiro: Tinta Negra.

FERNANDES, Fábio (2014). “Introdução" In: FAWCETT, Fausto. Santa Clara Poltergeist. Curitiba: Encrenca. p.11-16.

GINWAY, M. Elizabeth (2005). Fiç̧ão Científica Brasileira: Mitos Culturais e Nacionalidade no País do Futuro. São Paulo: Devir Livraria.

HEBDIGE, Dick (2008). Subculture: the meaning of style. New York: Routledge. KLEIN, Gérard (1977). "Discontent in American Science Fiction". Science Fiction Studies. Indiana. 4(11), March. In https://www.depauw.edu/sfs/backissues/11/ klein11.htm. Acesso em 27.Jul.2018.

LEVIN, Janna (2016). A música do universo: ondas gravitacionais e a maior descoberta científica dos últimos cem anos. São Paulo: Companhia das Letras. LONDERO, Rodolfo Rorato (2007). A recepção do gênero cyberpunk na literatura brasileira: o caso Santa Clara Poltergeist. (Dissertação de Mestrado em Estudos Literários) 178f. Universidade Federal do Mato Grosso do Sul, Três Lagoas.

(2010). "Entrevista com Fausto Fawcett". Santa Maria. Agosto. OverclockZine. In https://archive.org/stream/OverclockZine5/Overclock_ Zine_05_djvu.txt. Acesso em 27.Jul.2018.

(2013). Futuro Esquecido: a recepção da ficção cyberpunk na América Latina. Rio de Janeiro: Rizoma.

LÖWY, Michael; SAYRE, Robert (2015). Revolta e Melancolia. São Paulo: Boitempo. LUKÁCS, György (1965). Ensaios sobre Literatura. Rio de Janeiro: Editora Civilização Brasileira.

McCAFFERY, Larry (1991). "Cutting up: Cyberpunk, Punk Music, and Urban Decontextualizations". In McCAFFERY, Larry (org). Storming the reality studio: A casebook of cyberpunk and postmodern science fiction. London: Duke University Press. p.286-307.

PAIVA, Marcelo Rubens; NASCIMENTO, Clemente Tadeu (2016). Meninos em fúria: e o som que mudou a música para sempre. Rio de Janeiro: Alfaguara. 
RIDENTI, Marcelo (2010). Brasilidade revolucionária: um século de cultura e política. São Paulo: Editora Unesp.

ROBERTS, Adam (2018). A Verdadeira história da ficção científica: do preconceito à conquista das massas. Mário Molina (Trad.). São Paulo: Seoman.

ROVIRA, James (2018). Introduction: Theorizing Rock/Historicizing Romanticism. In: ROVIRA, James. Rock and Romanticism: Post-punk, Goth and Metal as Dark Romanticisms. London: Palgrave Macmillan. p.1-25

SCANLAN, John (2005). On Garbage. London: Reaktion Books.

SUVIN, Darko (1991). "On Gibson and Cyberpunk SF". In: McCAFFERY, Larry (Org). Storming the reality studio: A casebook of cyberpunk and postmodern science fiction. London: Duke University Press. p.349-365.

VIANA, Hermano (2014). Introdução. In: FAWCETT, Fausto. Santa Clara Poltergeist. Curitiba: Encrenca. p.7-9. 